\title{
O GESTO COMO ESPAÇO CONFIGURADOR DE UMA PESQUISA SOBRE A EXPERIÊNCIA
}

Beatriz Fabiana Olarieta ${ }^{1}$

"Há uma imensa diferença entre ver uma coisa sem o lápis na mão e vê-la desenhando-a. Ou melhor, são duas coisas muito diferentes as que vemos. Até mesmo o objeto mais familiar a nossos olhos torna-se completamente diferente se procuramos desenhá-lo: percebemos o que ignorávamos, que nunca o tínhamos visto realmente" ${ }^{2}$, afirma Valéry (2012, p. 61) pensando na arte de Degas. Depois de passar meses compartilhando encontros de filosofia com um grupo de crianças se aproximando vertiginosamente à adolescência ${ }^{3}$, agora que estamos com o lápis na mão ou com um teclado sob nossos dedos, sobre o que se posam os olhos? Que vemos? Os lápis e os teclados guardam um poderoso segredo: colocados a desenhar ou a escrever, transformam a experiência vivida. "Percebemos o que ignorávamos, que nunca o tínhamos visto realmente". A escrita de uma pesquisa ancorada na experiência, talvez, tenha por todo trabalho se entregar a isso que "ignorávamos, que nunca o tínhamos visto realmente", a dar visibilidade ao que era invisível, a permitir fazer-se presente àquilo que sempre esteve lá, mas que não percebemos no fragor da cotidianidade dos encontros com as crianças e com as professoras.

Uma pesquisa se gesta na escrita. Pode haver escrita sem pesquisa, mas sem escrita não há pesquisa. Tentaremos, então, pensar ao longo deste trabalho sobre isso no qual é necessário pousar os olhos uma vez que temos o lápis ou o teclado entre as mãos e nos dispomos a escrever nossa pesquisa.

Expectativas geradas. Corpos estreando a adolescência apertados na roda de conversa. O calor da sala. A ameaça dos mosquitos. O cheiro misturado da

\footnotetext{
${ }^{1}$ Faculdade de Educação da Universidade do Estado do Rio de Janeiro. Pesquisadora da FAPERJ. ${ }^{2}$ Grifo do autor

${ }^{3}$ A pesquisa que realizamos se desenvolve no marco das práticas do projeto de extensão de Filosofia com Crianças "Em Caxias, a filosofia em-caixa?" na Escola Municipal Joaquim da Silva Peçanha do município de Duque de Caxias no Estado do Rio de Janeiro. O projeto é coordenado pelo Núcleo de Estudos Filosóficos da Infância da Universidade do Estado do Rio de Janeiro.

OLARIETA, Beatriz Fabiana. O gesto como espaço configurador de uma pesquisa sobre a experiência. Revista Sul-Americana de Filosofia e Educação. Número 23: nov/2014abr/2015, p. 470-486.
} 
caixa dos lápis e da caixa dos papeis comprados com ilusão (nosso projeto de pesquisa pretendia que esses adolescentes, além de falar, escrevessem o que pensavam). As leituras. $\mathrm{O}$ barulho das cadeiras e das vozes. O esporádico silêncio da escrita coletiva. O trilhar do lápis sobre o papel. $\mathrm{O}$ inapreensível segundo que para o tempo perante alguma palavra lançada na roda que não permite ser digerida facilmente por nosso pensamento entregado ao hábito de reconhecer. $\mathrm{A}$ preparação dos encontros. As expectativas. A sensação de estar lutando contra o que se apresentava ou resistia a se apresentar. As horas que demorava o regresso num ônibus inevitavelmente preso no trânsito infernal das tardes das sextas-feiras no Rio de Janeiro. Algumas palavras (ditas ou escritas) ecoando. Alguns olhares gravados na memória.

Durante a experiência na escola e depois de atravessada a mesma nos acompanhou permanentemente a questão 'o que fazer?'. A essa questão agora temos que responder com escrita. A isso que vimos, que escutamos, que percebemos, a isso que se nos impus nos encontros com as crianças e do qual não conseguimos dar conta no momento, temos que responder com um teclado. Neste momento, é a própria escrita - e não a das crianças - a que se coloca em jogo. É a própria escrita através da escrita das crianças. É a escrita que tem que responder.

$\mathrm{O}$ que fazer dizer ao teclado de todo o vivido? Que risco traçar no papel que nos permita transitar pela ignorância que agora se revela? Onde posar nosso olhar para poder soltar a mão?

Peter Handke (HANDKE; HAMM, 2011, p. 57) nos dá uma pista:

“(...) escrever é um ato, talvez um colocar-em-vigor... o que deixamos passar. É a tentativa de fazer do que deixamos passar os lugares centrais do suceder do mundo e do mundo mesmo, ou pelo menos apontar, dar indicações com o dedo de que há uns acontecimentos distintos no mundo, um modo de suceder do mundo decididamente distinto e realmente dispensador de ânimo, além de ou junto ao que salta aos olhos todos os dias e entra em nossos ouvidos ou penetra em nosso nariz".

No texto de Handke poderíamos trocar a palavra escrever por pesquisar e, assim, a ação de pesquisar seria um cercar com a escrita esses atos que 
interromperam nossa continuidade, esses que deixam em evidência que nosso projeto ignorava aquilo que achava conhecido. Não deixá-los passar. Permitir que esses atos irrompam e interrompam, que tomem centralidade. Assinalá-los com o dedo, mesmo que sempre esse assinalamento chegue tarde demais, como quando se tenta mostrar uma estrela cadente a alguém que está distraído ao nosso lado e ela desaparece no preciso instante que seu olhar vai à sua procura. Não deixar que esses atos se esvaneçam sem ter brilhado antes.

$\mathrm{O}$ que seria isso que vai sendo visto e que, na hora de escrever, parece dar forma a experiência vivida? O que é isso que faz empalidecer as coisas mais obvias, as que pareciam ter tanta relevância no momento que estávamos lá enredando nosso corpo e nossa voz com as daqueles adolescentes, quando afanosamente semana a semana traçávamos nossos planos? Consideramos aqui que a experiência vivida encontra seus pontos de ancoragem na força dos gestos. São os gestos aos que devemos prestar nossos olhos neste momento porque neles se revela a potência do acontecido. São eles os que devem tomar centralidade, entrar em vigor para poder amarrar e ir tecendo o percurso de nossa pesquisa.

Não estamos fazendo referência aqui ao gesto como comunicação não verbal que transmite informação e que, como pesquisadores, deveríamos desentranhar ou interpretar. A tarefa não está em decifrar alguma mensagem que seria portada por esses corpos, por este rosto, por aquele papel, por esse silêncio, etc. O trabalho está em transitar pela interpelação, pela interrupção causada por eles. Essa interpelação não permite a interpretação fácil senão convoca ao silêncio porque nos revela nossa zona de ignorância, aquela onde se aloja o que não tínhamos visto (como diz Valéry), aquela na qual entra em vigor o que deixamos passar (como diz Handke).

\section{O gesto, o que sustenta}

As breves Notas sobre o gesto de Giorgio Agamben (2008) obrigam a dar atenção a cada linha, pela sua riqueza e sua capacidade de abrir todo um mundo para pensar acerca deste tema. 
O filósofo italiano, tomando a observação que Varrão fizesse na sua $D e$ lingua Latina, mostra um tipo de ação humana que se diferencia de um fazer sem agir (agere), próprio do poeta que faz um drama, mas não age, e de um agir sem fazer (facere), próprio do ator, que age - atua, mas não faz o drama. Entre estas duas possibilidades, para o gramático latino, existe um terceiro género na esfera da ação: o gesto. Ele é próprio do imperador e não consiste nem em fazer (produzir) nem em agir (atuar), mas em assumir, em suportar. O imperator (gerit), com respeito ao qual se usa a expressão res gerere, realiza algo, o coloca sobre si, no sentido de assumir completamente a responsabilidade, de apreendê-lo. É o suportar (sustinet) o que caracteriza ao gesto, o sustentar, o ter sobre si, o assumir. Nele nem se produz algo nem se age.

A distinção entre agere e fazere, remete à feita por Aristóteles na sua Ética a Nicómaco (VI 11, 40b) entre praxis e poiesis, adverte Agamben, mas esse terceiro tipo de ação destinado ao gesto é nova e própria de Varrão. Enquanto a ação da poiesis se apresenta como um meio encaminhado a alcançar um fim alheio ao próprio fazer, a praxis encontra seu fim no próprio agir. É um fim sem meio, pois é seu fim o próprio agir bem.

A particular forma de ação que é o gesto vem a quebrar essa falsa alternativa entre fins e meios, já que "(...) apresenta meios que, como tais, se subtraem ao âmbito da medialidade, sem por isso tornarem-se fins" (AGAMBEN, 2008, p. 13). O gesto se caracteriza, como dizia Varrão, por sustentar, por suportar $e$, como acrescenta Agamben, pela exibição de uma medialidade, por "tornar visível um meio como tal" (Idem). Ao gesto the são estranhos os fins alheios, ele não é um meio para alcançá-los. O gesto não se propõe em função de um destino pré-determinado, simplesmente suporta sobre si mesmo e exibe essa sua medialidade sem fim. Então, assim como o andar, esse deslocar-se do corpo de um ponto a outro, é um meio dirigido a um fim, a dança pertence ao território do gesto, dos meios sem fim. Não porque pertença a uma dimensão superior que faz do movimento um fim em si mesmo, mas porque nela o corpo suporta os movimentos e exibe seu caráter medial. Nela o corpo se torna meio sem uma finalidade alheia. 
O gesto é interrupção, é o impedimento, é falha, é impossibilidade.

\section{O gesto, o que profana}

Como pensar esse estranho modo de ação humana que seria um meio sem fim?

Em outro texto destinado a elogiar a profanação, Agamben (2007b) coloca outro exemplo de meio sem fim: o gato brincando com o novelo. Acontece que o brincar é uma forma de profanação.

Antes de continuar com o exemplo, vejamos como Agamben pensa a profanação. Profano é aquilo que "(...) é restituído ao uso comum dos homens" (Ibidem, p. 65). O filósofo conta como a profanação se produz de duas formas. Uma das maneiras de profanar é pelo contato. Quando uma vítima é oferecida em sacrifício aos deuses, uma parte dela está reservada a eles, mas o que sobra pode ser consumido pelos homens. É suficiente que quem participa do ritual toque a carne para que o encanto desapareça e esses restos voltem aos homens, se contagiem, se tornem profanos.

Então, profana quem toca e é profanado o que é tocado por alguém. Profana quem faz, de algum modo, parte de si aquilo que era sagrado, quem rouba dos deuses o que eles se apropriaram, quem restitui ao uso comum, quem faz parte de sua carne essa carne que era sagrada.

Agamben traça uma etimologia da palavra religião distinta daquela que, tão comumente, a vincula a religare (o que liga, o que une o divino e o humano). Coloca-a em relação com relegere, que indica um sentido oposto, dado que assinala a atenção, a hesitação (o 'reler') que deve imperar na relação com o mundo divino no que se refere às formas que devem ser seguidas para manter a separação entre o sagrado e o profano. Por tanto, a religião não é o que liga estes dois mundos, mas, antes, o que garante a separação. A profanação atua sobre esta separação. "Profanar significa abrir a possibilidade de uma forma especial de negligência, que ignora a separação, ou melhor, faz dela um uso particular" (Ibidem, p. 66). 
Além do contato, a profanação também se produz por uso, ou como prefere dizer Agamben, por um reuso. Um claro exemplo desse reuso é o brincar. $\mathrm{O}$ jogo tem suas origens vinculadas ao mundo religioso, ao espaço onde mito e rito se encontram. Mas o jogo separa essas duas instâncias e desarticula a potência do ato sagrado ao ficar apenas com a metade da operação. “(...) Como ludus, ou jogo de ação, faz desaparecer o mito e conserva o rito; como jocus, ou jogo de palavras, ele cancela o rito e deixa sobreviver o mito" (Ibidem, p. 67).

A profanação produz uma neutralização daquilo que profana por uma espécie de negligência. "O jogo libera e desvia a humanidade da esfera do sagrado, mas sem abolir simplesmente. O uso ao que o sagrado é devolvido é um uso especial, que não coincide com o uso utilitarista" (Idem). A criança que brinca transforma em brinquedo qualquer coisa que chega a suas mãos outorgando uma nova dimensão do uso a objetos que provém do considerado mundo sério. "(...) A religio não mais observada, mais jogada abre a porta para o uso, assim também as potencias da economia, do direito e da política, desativadas em jogo, toram-se a porta de uma nova felicidade" (Idem).

Então, profana-se ao dar outro uso, ao reusar, ao desviar da esfera do sagrado, ao fugir do destino que os deuses tinham previsto. Profana-se ao negligenciar o que nos separa deles ao devolver-nos o que eles se levaram. Profana-se ao entregar as coisas a um mundo não utilitarista. Profana-se ao brincar.

Agora podemos ver por que o gato brincando com o novelo é um profanador e por que essa atividade é um meio sem fim - essa qualidade que caracteriza ao gesto. Ao brincar, o gato está utilizando as habilidades da caça, mas ao substituir o rato pelo novelo liberta não só ao rato do fato de ser uma pressa, mas também a essas habilidades predatórias da finalidade para a qual foram geneticamente destinadas, as esvazia de seu sentido e da relação imposta por sua finalidade. "O comportamento libertado dessa forma reproduz e ainda expressa gestualmente as formas da atividade de que se emancipou (...)" (Ibidem, p. 74). A atividade resultante torna-se um puro meio, embora conserve sua natureza de meio dado. O gato apresenta os mesmos comportamentos que definiam a caça, 
mas estes, libertados de sua finalidade, esqueceram "(...) alegremente o seu objetivo, podendo agora exibir-se como tal, como meio sem fim” (Ibidem, p. 75).

Esse alegre esquecimento não é uma perda de memória. Essa negligência do meio sem fim não tem a ver com um descuido, nem com a indiferença, mas com uma nova dimensão do uso que desativa, que deixa sem efeito ou sem efetividade. Não é um combate por oposição que busca a eliminação daquilo que negligencia. Não é simplesmente a abolição ou cancelamento das separações, mas um jogo que reconfigura e torna possível um novo uso, que traça um novo plano no qual a separação se torna inoperante. O que tinha sido retirado do uso comum e tornado sagrado, por um ato de profanação (ou por um gesto profanatório) é neutralizado e restituído ao uso comum.

\section{Um gesto: Edna, Lucas Daniel e um sussurro}

Convido aqui a nos deter sobre um gesto inesperado, uns dos tantos que aconteceram na minha presença quando eu estava tentando levar a frente um projeto de pesquisa sobre a escrita de uma turma nos encontros de filosofia com crianças em uma escola pública.

Naquela ocasião, estávamos lembrando as questões que foram colocadas no encontro anterior a partir dos textos que foram escritos pelo grupo, tentando experimentar se é possível escrever sobre o que não sabemos. Durante a conversa aparece 'o nada' como um exemplo de algo totalmente desconhecido e sobre o que, hipoteticamente, seria impossível escrever. A questão colocada, a partir daí, foi se é possível escrever sobre o nada. Não importa aqui apresentar toda a conversa. O que nos interessa é um gesto: o de Lucas Daniel, um dos adolescentes envolvidos. Ou melhor, dois gestos. Ou melhor ainda, um gesto duplo: o de Lucas Daniel e o de Edna, sua professora de português que havia cedido uma hora semanal de sua disciplina para nosso projeto e participava também dos encontros. Enquanto a discussão se desenvolvia, Lucas levanta de sua cadeira, se aproxima a Edna, lhe sussurra algo e volta a sentar. Pegamos a conversa já começada: 
LAWANY: A gente pode escrever sobre o nada, como algo inexplicável de cor branca. Sei lá... Pode descrever uma coisa que não se pode explicar: uma sala vazia. Tem como escrever sobre o nada sim.

ARTHUR: Você pode dar um sentido. Se eu quero escrever sobre o nada, eu não vou tentar dar uma resposta sobre o nada, mas vou tentar dar um significado para mim sobre o nada.

FABIANA: Você usou duas palavras: sentido e significado. São a mesma coisa?

ARTHUR: Sentido, significado... Vou tentar dar um sentido do nada para mim.

LAWANY: É só escrever "o nada é inexplicável".

MATHEUS AUGUSTO: Mas, quando você fala, você já está explicando.

LUCAS DANIEL se dirigindo a mim diz: Professora, eu acho que esse assunto sobre o nada não vai dar em nada (risos). Seria legal se na próxima aula a gente escrevesse sobre isso.

Depois soube que era isso o que ele tinha falado baixinho para Edna $e$ estava esperando a ocasião de colocar para o grupo. Ele queria que escrevêssemos sobre o nada.

EDNA o apoia: Não, na próxima aula não, a gente pode escrever sobre o nada agora.

FABIANA: Então, o desafio foi lançado, vamos tentar escrever sobre o nada?

Buscamos folhas e lápis e todo o mundo tentou escrever algo.

LUCAS DANIEL quer ser o primeiro em ler: "O nada pode ser um quarto vazio, um deserto sem areia, um rio sem água. $O$ nada simplesmente é o nada" 4.

LUANA: Você me copiou. Eu escrevi assim "O nada é o nada, exemplo, nada".

FABIANA: Que bonito o que você escreveu, Lucas. Quem mais achou a chave secreta da palavra nada? (em referência a um poema de Drummond que tínhamos lido)

Todos foram lendo e chegou a vez da professora de português.

EDNA: Eu fiz um desenho. É um caminho dentro de mim que eu não sei nem o começo nem o fim.

\footnotetext{
${ }^{4}$ Isso é o que Lucas leu. O texto escrito por ele, literalmente, diz: "O nada e simplesmente nada e como eu vou escrever sobre o nada pode sem um quarto escura vasio um deserto sem areia um rio sem água. O nada tem simplesmente nada que em dentro de mim".
} 
FABIANA: Mas, Edna, isso que você fez é escrita? Você desenhou?!

EDNA: Sim, é um desenho, eu não consegui escrever com palavras.

Nas jornadas do projeto de extensão desse ano, compartilhando sua experiência com colegas de escolas que possivelmente estariam interessadas em ser parte de nossa prática de filosofia na escola, Edna contou como esse desafio de seu aluno a tocou. Foi essa a primeira vez que um aluno a convidou a escrever. Um movimento contrário ao que ela estava acostumada. A tradição escolar diria que é ela, enquanto professora de português, quem deve estimular a escrita de seus alunos, mas Lucas Daniel subverteu essa lógica, ou melhor: a negligenciou. Não sabemos por que, simplesmente, ele não lançou o convite para o grupo e primeiro o fez à sua professora de português. Talvez buscasse autorização, talvez cumplicidade. Não interessa. A questão é que essa, sua professora, foi convidada pessoalmente por seu aluno e sentiu que não pôde responder, ou melhor, experimentou a impossibilidade de dar resposta. Lucas Daniel tinha escrito um texto lindo e ela só conseguiu deixar correr os traços de um desenho sobre o papel porque não tinha palavras. Seus conhecimentos da língua portuguesa não puderam auxiliá-la nesse momento.

Luana acusa a Lucas Daniel de tê-la copiado. Encontramos esse "deserto sem areia" também no texto do Tiago e esse "quarto vazio" no de Emilly. Não interessa. O gesto que sustenta essas linhas foi muito mais poderoso que essas palavras. Essas palavras colocaram em xeque a gramática e a sintaxe de sua professora de português, levaram-na a se deparar com um lugar ou uma posição desconhecida para ela.

Se misturássemos o texto de Edna entre os de seus alunos e pedíssemos para achar no baralho o que foi feito pela professora de português, dificilmente alguém adivinharia que esse desenho modesto, desamparado entre tantas palavras, lhe pertence. Também não saberia que esse desenho não fala de alguém que não sabe escrever, mas de alguém que foi colocada em situação de não poder mais escrever; que viu-se posta em situação de ter que suspender a sua escrita $e$ dissimular nas linhas de um desenho a falta de palavra. Esse desenho faz lugar a 
esse silêncio, a essa impossibilidade. Ao suportar o vazio abre lugar ao gesto que sustenta a própria impossibilidade de Edna e também dá sustento ao gesto de Lucas que, profanando seu lugar de aluno, convida a escrever a sua professora. Dois gestos se provocando, se oferecendo maravilhosa e gratuitamente um ao outro numa sala de uma escola pública. Duas formas de proceder, de entrar em ação que não procuram um efeito, que não buscam nada além de si mesmas, que renunciam a qualquer finalidade e em isso alojam sua potência. Essa potência capaz de profanar os lugares estabelecidos pela instituição: o da professora que domina a língua e manda a escrever e o do aluno que deve aprender e exercitar-se segundo as orientações da professora que ensinará os segredos escondidos nessa língua que ele fala, mas não domina.

\section{Gesto e linguagem}

A irrupção do gesto interrompe o meio “(...) em seu próprio ser-meio e apenas assim o exibe, faz de uma res uma res gesta" (AGAMBEN, 2008, p. 13).

Desde o ponto de vista da linguagem, fazer da palavra um gesto, não implica fazer dela um meio de comunicação, fazer uso dela como se fosse algo que escapa à própria linguagem (uma metalinguagem), que se encontra em um plano mais elevado e que permitiria transformar a experiência em objeto de comunicação. Mostrar uma palavra é “(...) expô-la sem nenhuma transcendência na sua própria medialidade, no seu próprio ser meio. O gesto é, neste sentido, comunicação de uma comunicabilidade. Este não tem propriamente nada a dizer, porque aquilo que mostra é o ser-na-linguagem do homem" (AGAMBEN, 2008, p. 13). Mas, as palavras e suas combinações em proposições são incapazes de dizer. Elas só transmitem informações, significados. O gesto implica, neste sentido, se colocar na boca uma impossibilidade de falar e na mão uma impossibilidade de escrever. $\mathrm{O}$ gesto implica um desnudar esse impedimento intrínseco à palavra que jamais poderá fechar o sentido, que jamais poderá contemplar assepticamente à distância, que poderá construir a ilusão de ser um simples meio que comunica, mas que para ter a densidade do verdadeiro deverá abandonar essa fictícia distância protetora e se assumir e ter a coragem de renunciar à transcendência $e$ se expor 
nessa sua impossibilidade, nessa sua medialidade sem fim, nessa sua gestualidade. Porque o gesto é "(...) o que continua inexpresso em cada ato de expressão" (AGAMBEN, 2007a, p. 59). Porque “(...) o gesto é, na sua essência, sempre gesto de não se entender na linguagem, é sempre gag no significado próprio do termo, que indica, antes de tudo, algo que se coloca na boca para impedir a palavra, $e$ também a improvisação do ator para superar uma falha de memória ou uma impossibilidade de falar" (AGAMBEN, 2008, p. 13-14).

É essa falha de memória, esse incurável defeito da fala, essa impossibilidade o que o gesto de Edna e de Lucas Daniel suporta, sustenta e assume.

\section{O gesto, um pôr-se em jogo e uma ausência}

Esse gesto dá sustento, suporta também no sentido em que coloca o corpo a disposição, oferece a própria vida. A professora suporta o desafio lançado por seu aluno. Renuncia ao resguardo que lhe oferece o papel institucional e oferece sua carne desprovida de qualquer roupagem à escrita solicitada por ele. Ai se depara com que suas mãos que foram treinadas por anos para a tarefa, são incapazes de escrever. A voz desse corpo desorientado deve dizer perante sua turma que essa, sua professora de português, foi incapaz de escrever. Edna se entrega ao jogo. Edna se põe existencialmente em jogo.

Junto a esse gesto está o gesto de quem, pretendendo desenvolver uma pesquisa, estava ali e presenciou essa posta em cena, esse instante em que eles se põem em jogo. Os gestos como os de Edna e Lucas Daniel não permitirão que deles tomemos uma distância de pretendida objetividade. Por uma parte, não nos conduzirão a saber quem são substancialmente nem biograficamente esses sujeitos. Esses gestos também não permitem explicar ou analisar o funcionamento da instituição escolar com respeito à escrita, nem sequer o funcionamento dessa escola particular que eles habitam ou inferir a partir de sua conduta o papel de alunos $e$ professores na hora de escrever o que se pensa ao interior da experiência de filosofar na escola. Esses gestos expõem o vazio que portam. Perante eles, talvez, o lugar que caiba a quem pesquisa uma experiência não seja mais que o de ser testemunha dessa cena que nada pretende, que simplesmente se expõe, se oferece 
gratuitamente em toda sua medialidade - como o faz o corpo em uma dança - a quem decida presta-lhe os olhos, os ouvidos, o corpo, para quem decida pôr-se em jogo.

Mas, de que forma uma vida se põe em jogo?

Em 1977, Michel Foucault escreve o que pretendia transformar em prólogo de uma antologia documentos dos séculos XVII e XVIII provenientes de arquivos de internato, da polícia, das petições ao rei e das cartas régias com ordens de prisão. Esse texto é $A$ vida dos homens infames (2003). Nele o autor apresenta o sentido de recopilar uma série de documentos que testemunhassem brevemente a existência de vidas obscuras e desventuradas, “(...) que tivessem feito parte realmente da história minúscula dessas existências, de sua desgraça, de sua raiva ou de sua incerta loucura" (Ibidem, p.206). Não seriam esses textos, escritos que se colocassem a uma certa distância da realidade, mas, pelo contrário, em direta relação com ela, operando sobre ela. Foucault busca documentos que “(...) constituíssem o instrumento de uma vingança, a arma de um ódio, um episódio de uma batalha, a gesticulação de um desespero ou de um ciúme, uma súplica ou uma ordem" (Idem).

O filósofo não pretende reunir documentos em função de seu valor representativo ou da capacidade de reconstruir a biografia de seus protagonistas, mas fragmentos fugazes atravessados pela vida e que atravessam vidas, a existência de vidas anônimas. Existências riscadas e perdidas nessas palavras.

"Não é uma compilação de retratos que se lerá aqui: são armadilhas, armas, gritos, gestos, atitudes, astúcias, intrigas cujas palavras foram os instrumentos. Vidas reais foram 'desempenhadas" nestas poucas frases; não quero dizer com isso que elas ali foram figuradas, mas que, de fato, sua liberdade, sua infelicidade, com freqüencia sua morte, em todo caso seu destino foram, ali, ao menos em parte, decididos" (Ibidem, p. 206-207).

\footnotetext{
${ }^{5}$ Grifo do autor.
} 
$\mathrm{Na}$ tradução ao português, essas vidas foram 'desempenhadas', mas o verbo francês usado por Foucault e que Giorgio Agamben (2007a) resgata é jouer (jogar, pôr em jogo). Ao ler esses fragmentos, Foucault confessa:

“(...) essas 'notícias', surgindo de repente através de dois séculos de silêncio, abalaram mais fibras em mim do que o que comumente chamamos literatura, sem que possa dizer, ainda hoje, se me emocionei mais com a beleza desse estilo clássico, drapeado em algumas frases em torno de personagens sem dúvida miseráveis, ou com os excessos, a mistura de obstinação sombria e de perfídia dessas vidas das quais se sentem, sob as palavras lisas como a pedra, a derrota e o afinco" (Foucault, 2003, p. 204).

Foucault quer fazer essa compilação porque não quer permanecer mais à margem da intensidade que esses documentos portam. Entre eles encontramos a uma anônima astróloga sendo levada a prisão porque "há poucos crimes que ela não tenha cometido, e nenhum de que ela não seja capaz" (Ibidem, p. 212); é por isso que se transforma em caridade a justiça de livrar à sociedade de seus enganos, roubos e escândalos. Ou a Duschesne, um funcionário subalterno, lançando-se desesperadamente aos pés de sua Majestade para implorar justiça contra sua esposa, "a mais malvadas de todas as mulheres (...) despojada de qualquer sentimento de religião, de honra, de probidade e mesmo de humanidade" (Idem, p. 211), que sistematicamente se nega a responder aos esforços por reconduzir sua vida, primeiro, a base de doçura e, depois, de admoestações. Ou a Mathurin Milan entrando no hospital por se esconder de sua família e "vaguear seu pobre espírito por estradas desconhecidas" (Ibidem, p. 204). Ou a Jean Antoine Touzard encerrado no Chateau Bicêtre por apóstata, ateu e sodomita, "um verdadeiro mostro de abominação que seria menos inconveniente sufocar do que deixar livre" (Idem).

Foucault percebe que nessas partículas ínfimas que se conservaram ao longo dos séculos, existências tão miúdas quanto elas estão sendo 'postas em jogo' (jouées), que no rasto escrito dessas denúncias, dessas súplicas, dessas ordens de prisão ou de internamento - solicitadas na maioria das vezes pelos familiares do 
acusado, existências minúsculas saem com uma estranha beleza à luz para tornarse cinzas.

Essas vidas anônimas cujo destino esperável teria sido o de desaparecer tão invisíveis quanto surgiram, ao se encontrar com o poder, são iluminadas fugazmente. É por isso que temos notícias delas. É pela atenção que o poder lhes deu que contamos com algumas palavras que as iluminam no momento em que seu destino está sendo decidido. Nada saberemos da vida desses seres como Mathurin Milan ou de Jean Antoine Touzard fora dessas denúncias, dessas queixas, dessas solicitações, dessas súplicas. Nada fora desses momentos cruciais em que suas vidas estão sendo 'postas em jogo' (jouées).

Agamben (2007a) chama a atenção sobre a ambiguidade do verbo jouer. Ele também tem um significado teatral. 'Pôr em jogo' pode ser lido também como colocar em cena. Esse sentido é possível porque tem alguém que coloca em cena e que permanece na sombra. Pergunta-se o filósofo, quem 'pôs em jogo' (em cena) a vida desses homens infames? Poderíamos pensar que eles próprios ao insistir em suas condutas consideradas perniciosas. Poderíamos, talvez, considerar como responsável a urdidura perversa tecida por familiares, funcionários, policiais, etc.

\footnotetext{
"A vida infame não parece pertencer integralmente nem a uns nem a outros, nem aos registros dos nomes que no final deverão responder por isso, nem aos funcionários do poder que, em todo caso, e no final das contas, decidirão a respeito dela. Ela é apenas jogada, nunca possuída, nunca representada, nunca dita - por isso ela é o lugar possível, mas vazio, de uma ética, de uma forma-de-vida" (AGAMBEN, Ibidem, p. $60)$.
}

Viver eticamente nada tem a ver com a submissão à lei moral, com ajustar a própria existência a um conteúdo, mas com uma "forma-de-vida". Uma vida se vive eticamente quando se 'põe em jogo' sem reservas em seus gestos, "mesmo correndo o risco de que dessa maneira, venham a ser decididas, de uma vez por todas, a sua felicidade e a sua infelicidade" (Idem).

Assim como os homens infames, o gesto ético, a vida que se 'põe em jogo', tem a ver com um tipo estranho de presença, com um espaço que não pode dizer ou representar essa vida, com uma borda inexpressiva que é iluminada por um 
feixe de luz. Mas é precisamente isso que permanece ilegível, esse lugar vazio, o que faz possível sua leitura. Para poder tomar contato com essas vidas infames é necessário se colocar nesse lugar vazio, é necessário também pôr-se em jogo.

Como tomar contato com essas vidas infames? Onde habitam esses seres dos quais ignoramos quase todo exceto o que nos revelam esses pingos de palavra? Onde estão Mathurin Milan e Jean Antoine Touzard? "Estão no umbral do texto em que foram postos em jogo, ou quem sabe, a sua ausência, o seu voltar as costas para nós para sempre se põem nas bordas do arquivo, como o gesto que ao mesmo tempo, o tornou possível e lhe excede e anula a intenção" (AGAMBEN, 2007a, p. 60).

Podemos pensar que nos aproximamos aos gestos, essas fugazes formas de 'por em jogo' a própria vida, essa singular maneira de agir que implica um colocarse em risco, um habitar essa ausência, um andar por esse vazio, quando nós também nos colocamos em jogo, quando renunciamos a possuir, a representar, a explicar, a comunicar, quando suportamos a intempérie da linguagem.

Nesse sentido, encontrando-nos lançados nessa plateia onde se jogam cenas como a de Edna e Lucas Daniel, talvez possamos nos pensar como autores de uma pesquisa. Como afirma Agamben (2007a, p. 63), inspirado por Foucault, "o autor não é mais que a testemunha, o fiador da própria falta na obra em que foi jogado".

Abrir um espaço onde quem escreve não pare de desaparecer para que apareça aquilo que se vê quando se está com o lápis ou teclado entre as mãos, quando os contornos das coisas não parecem tão claros e definidos, quando o que se ignora se torna evidente e quando não queda mais que 'pôr-se em jogo'.

\section{Pesquisar, a tarefa de despertar os gestos}

Voltando ao início do texto, esse 'colocar-em-vigor' que assinalava Handke, talvez possa ser pensado como um colocar em vigor gestos.

A cena protagonizada por Lucas Daniel e por Edna, não é uma cena estática, uma fotografia rígida $e$ isolada de algo que aconteceu durante o desenvolvimento de nosso projeto de pesquisa, ou melhor, 'apesar' de nosso projeto que, como todo projeto, nasceu de um movimento contrário ao gesto, 
escondendo fins segredos que pretendia alcançar, tentando torcer destinos para seu próprio proveito. Esta imagem deveria ser pensada, como sugere Agamben (2008), como um fotograma, como o fragmento de um filme. De fato, toda imagem convive com a tensão polar entre, de um lado a imobilidade e eternidade da "imago como máscara de cera do morto ou como símbolo" (Ibidem, p. 12) e, nesse sentido, anulação do gesto que apela à memória voluntária e, do outro lado, a conservação da dynamis que "lampeja na epifania da memória involuntária" (Idem) e que envia sempre para além de si mesma. "Pois, em toda imagem está sempre em ação uma espécie de ligatio, um poder paralisante que é preciso desencantar" (Idem), um chamado a libertar essa imagem no gesto, a deixar que ela adquira vida, ou melhor, que conserve a vida que porta. A cena de Edna e Lucas Daniel é impossível de congelar, ela não é trazida voluntariamente à memória, ela aparece quando se está com um teclado entre os dedos. Por um breve instante, a força dessas vidas sendo 'postas em jogo', suportando, assumindo esse instante, profanando, cutuca, punça por sair à luz, se impõe em toda sua vitalidade, com toda sua força.

Agamben (2008, p. 12) elabora, inspirado em Beckett, uma bela definição do cinema, essa arte que conhece de gestos: “(...) o cinema é o sonho de um gesto. Introduzir neste sonho o elemento do despertar é a tarefa do diretor”. Talvez a tarefa da escrita do pesquisador, ao modo de um diretor de cinema, não seja mais que despertar os gestos que sonharam na sua presença.

\section{Referências}

AGAMBEN, Giorgio. Medios sin fin. Valencia: Pre-textos, 2001.

. "O autor como gesto". In: . Profanações. São Paulo: Boitempo, 2007a, p 55-63.

. "Elogio da profanação" In: . Profanações. São Paulo: Boitempo, 2007b, p. 65-79.

. "Notas sobre o gesto". Artefilosofia. Ouro Preto: Instituto de Filosofia, Artes e Cultura, Universidade Federal de Ouro Preto, Tessitura, n. 4, jan. 2008. p. 9-14. 
CASTRO, Edgardo. Giorgio Agamben: Una arqueologia de la potencia. Buenos Aires: Jorge Baduino Ediciones, Universidad Nacional de San Martín, 2008.

FOUCAULT, Michel. "A vida dos homens infames". In: Ditos e Escritos: Estratégia, poder-saber. Vol. IV. Rio de Janeiro: Forense Universitária, 2003, p. 203-222.

HANDKE, Peter; HAMM, Peter. Vivan las ilusiones: Conversaciones en Chaville y otros lugares. Valencia: Pre-textos, 2011.

VALÉRY, Paul. Degas dança desenho. São Paulo: Cosac Naify, 2012. 